\title{
Do Biometeorological Indices Improve Modeling Outcomes of Heat-Related Mortality?
}

\author{
PAVLA VANECKOVA \\ School of Public Health and Institute of Health and Biomedical Innovation, Queensland \\ University of Technology, Brisbane, Queensland, Australia \\ GERARD NEVILLE \\ Environmental Health Branch, Queensland Health, Brisbane, Queensland, Australia
}

VIVIENNE TIPPETT

Australian Centre for Prehospital Research, Queensland Ambulance Service, Brisbane, Queensland, Australia

PETER AITKEN

James Cook University, Townsville, Queensland, Australia

GERARD FitzGERALD AND SHILU TONG

School of Public Health and Institute of Health and Biomedical Innovation, Queensland

University of Technology, Brisbane, Queensland, Australia

(Manuscript received 26 August 2010, in final form 21 January 2011)

\begin{abstract}
Various biometeorological indices and temperature measures have been used to assess heat-related health risks. Composite indices are expected to assess human comfort more accurately than do temperature measures alone. The performances of several common biometeorological indices and temperature measures in evaluating the heat-related mortality in Brisbane, Australia - a city with a subtropical climate-were compared. Daily counts of deaths from organic causes [International Statistical Classification of Diseases and Related Health Problems, 9th Revision, (ICD9) codes 001-799 and ICD, 10th Revision, (ICD10) codes A00-R99] during the period from 1 January 1996 to 30 November 2004 were used. Several composite biometeorological indices were considered, such as apparent temperature, relative strain index, Thom discomfort index, the humidex, and wetbulb globe temperature. Hot days were defined as those days falling into the 95th percentile of each thermal stress indicator. Case-crossover analysis was applied to estimate the relationship between exposure to heat and mortality. The performances of various biometeorological indices and temperature measures were compared using the jackknife resampling method. The results show that more deaths were likely to occur on hot days than on other (i.e., control) days regardless of the temperature measure or biometeorological index that is considered. The magnitude of the odds ratios varied with temperature indicators, between 1.08 [95\% confidence interval (CI): 1.02-1.14] and 1.41 (95\% CI: 1.22-1.64) after adjusting for air pollutants (particulate matter with aerodynamic diameter less than $10 \mu \mathrm{m}$ and ozone). Average temperature performed similarly to the composite indices, but minimum and maximum temperatures performed relatively poorer. Thus, average temperature may be suitable for the development of weather-health warning systems if the findings presented herein are confirmed in different locations.
\end{abstract}

Corresponding author address: Dr. Pavla Vaneckova, School of Medicine, University of Western Sydney, Locked Bag 1797, Penrith, NSW 2751, Australia

E-mail: apawnr@gmail.com

\section{Introduction}

Heat stress is a significant health concern and has been previously associated with substantial excess mortality (e.g., Fouillet et al. 2006; Smargiassi et al. 2009), as has 
been documented during heat waves in Europe, the United States, and Australia (e.g., Semenza et al. 1996; Fouillet et al. 2006; Tong et al. 2010). Previous studies have used a variety of heat stress measures (e.g., maximum and minimum temperatures, apparent temperature, and biometeorological and human comfort indices) to assess the vulnerability of populations to heat stress (e.g., Höppe 1999; Spagnolo and de Dear 2003; Nicholls et al. 2008; Barnett et al. 2010).

An essential requirement for normal body function is that the human body constantly regulates its internal temperature with the surrounding environment through several mechanisms of heat exchange. When the body reaches thermal equilibrium with the surrounding environment, thermal comfort occurs (Kerslake 1972). According to the American Society of Heating, Refrigerating, and Air-Conditioning Engineers (ASHRAE 2004), thermal comfort is "that condition of mind which expresses satisfaction with the thermal environment." The perception of thermal comfort (or thermal stress) is complex and results from synergistic effects of environmental, physiological, and behavioral variables such as temperature, humidity, air movement, solar radiation, metabolic rate, age, physical activity, and clothing (Budd 2008). Accounting for all of these elements is hardly manageable because of the complexity of the measures, the limited availability of the input variables, and, in some cases, the invasiveness of such techniques. Therefore, for the purpose of modeling the impact of heat stress in epidemiological studies, simplified measures of thermal stress are generally used.

Although a large number of measures to estimate thermal stress have been developed, a single temperature measure (such as average or maximum temperature) continues to be the most common proxy for thermal discomfort in epidemiological research. Previous studies have also used indices (such as apparent temperature) that combine temperature and humidity because this has been suggested to approximate better how the temperature actually affects the body (O'Neill et al. 2003; Watts and Kalkstein 2004; Budd 2008). More complex indices based on wind component, solar radiation, and atmospheric pressure have also been employed (Kalkstein et al. 1996; Höppe 1999; Sheridan and Kalkstein 2004).

Rarely is more than one measure of thermal stress used in a study; thus, the predictive ability of various measures and their suitability to a specific geographic location are not yet well understood (e.g., Conti et al. 2007; Zanobetti and Schwartz 2008; Anderson and Bell 2009). Metzger et al. (2010) recently compared several heat-stress measures in New York for the period between 1997 and 2006 and found similar results regardless of the measure used. Barnett et al. (2010) compared several temperature measures in many U.S. cities for the period between 1987 and 2000. Although they found large differences in the best temperature measures across different regions, age groups, and seasons, overall none of the measures was deemed superior. They also observed that these temperature measures had similar predictive ability as a result of their strong correlation. They proposed that the best temperature measure for new studies can be chosen based on practical concerns, such as minimizing the amount of missing data. In a similar way, Hajat et al. (2010) used four different approaches to define heat-dangerous days in four cities with various climates. Little agreement on the selection of heatoppressive days was found among these approaches, and the selected days were not systematically associated with a higher number of deaths. Another study found differences in the impacts of several temperature measures on health (Nicholls et al. 2008). More research is needed to clarify this issue.

During extremely hot days, higher concentrations of air pollutants, such as ozone $\left(\mathrm{O}_{3}\right)$ and particulate matter with diameter of less than $10 \mu \mathrm{m}\left(\mathrm{PM}_{10}\right)$, have been previously documented (e.g., Roberts 2004; Papanastasiou et al. 2010). Meteorological conditions on such days can foster the formation of photoreactive pollutants, such as ozone (Hart et al. 2006). In addition, $\mathrm{PM}_{10}$ can occur in higher concentrations because of increased production of secondary aerosols during days with high ambient temperatures (Morawska et al. 2002). Air pollution is known to have adverse effects on human health and can confound/modify the heat-mortality relationship (Ren et al. 2008; Stafoggia et al. 2008). Therefore regional assessments of the role of air pollutants during hot weather conditions are important. Previous studies that compared the performances of several biometeorological indices rarely adjusted for the presence of air pollutants (e.g., Barnett et al. 2010; Metzger et al. 2010).

To date, systematic assessments of the efficiency of several indices and temperature measures, as well as comparisons of their ability to predict heat-related deaths on a specific population, have rarely been conducted. The aim of our study is to compare the performances of several relatively simple and frequently used biometeorological indices and three measures of temperature in evaluating heat-related health impact after adjusting for air pollution.

In the next section we present the datasets and indices that we used in this study. We also describe the statistical methods used, and then the results. Next, we discuss our results in the context of international and local relevance, and suggest future research directions. 


\section{Materials and methods}

\section{a. Data sources}

The Office of Economic and Statistical Research of the Queensland Treasury provided daily mortality counts for the Brisbane, Australia, local governmental area (LGA) for the period between 1 January 1996 and 30 November 2004. The cause of death was classified according to the International Statistical Classification of Diseases and Related Health Problems 9th and 10th Revisions (ICD9 and ICD10) codes. Only organic causes of death (excluding deaths due to injury, ICD9 codes 001-799 and ICD10 codes A00-R99) were considered in this study.

The Australian Bureau of Meteorology (BOM) provided the meteorological variables for the study period. These included daily measurements of air temperature $\left({ }^{\circ} \mathrm{C}\right)$, water vapor pressure $(\mathrm{hPa})$, wind speed at an ele-

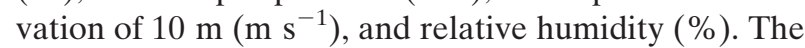
Archerfield Airport meteorological station (World Meteorological Organization index number 94575; BOM station number 40211) is located southwest of the Brisbane central business district $\left(\mathrm{CBD} ; 27.5^{\circ} \mathrm{S}, 153.0^{\circ} \mathrm{E}\right)$. This is a high-quality station and contains a more complete record than do other stations within the region. It is also assumed to provide a better approximation to the temperature exposure of the population than the other high-quality station available, the Brisbane Airport station, located on the coast and therefore farther from the most populated areas and subject to frequent sea breezes. The temperature records at the Brisbane Airport station would likely underestimate the summer conditions in some locations around Brisbane.

Daily data on 24-h concentrations of $\mathrm{O}_{3}$ and $\mathrm{PM}_{10}$ were obtained from the Queensland Department of Environment and Resource Management (DERM). The air pollution data were measured at the Brisbane CBD station, which is located on the Queensland University of Technology campus in a commercial business area (DERM 2010). Because of its elevated position, this monitoring site is less biased toward any source of particulate matter emissions than are other stations nearby that are not elevated and are often located close to major roads (because their goal is to measure the local emissions). The Brisbane CBD station consequently provides a better measure of the $\mathrm{PM}_{10}$ levels to which the majority of the population of the Brisbane LGA is exposed. The $\mathrm{O}_{3}$ distribution across Brisbane is fairly homogeneous, and therefore any station could be used for measuring the exposure to $\mathrm{O}_{3}$ (Morawska et al. 2002). Both meteorological and air-pollutant stations were chosen as being representative for the Brisbane LGA.

\section{b. Biometeorological indices}

We used daily measurements of maximum, minimum, and average temperature and several biometeorological indices. All three types of temperature measurement have been previously used in heat-related research, and there is currently no evidence of any one measure being superior to the others (Barnett et al. 2010), although average and maximum temperatures are more frequently used than is minimum temperature. The three temperature measurements are usually highly correlated, but also measure slightly different daily exposure experiences. We therefore evaluated the performances of all three temperature measures.

Several biometeorological indices were constructed from commonly available meteorological variables. These indices included the wet-bulb globe temperature (WBGT), apparent temperature (including and excluding the wind component: ATW and AT, respectively), Thom discomfort index (DI), relative strain index (RSI), and "humidex." Most of the indices are a combination of temperature and some measurement of humidity; one index (ATW) also includes the wind component. All indices aim at reflecting the subjective "perceived temperature." A more detailed description of these indices is available in Table 1.

\section{1) WBGT}

WBGT is a composite temperature index developed more than 50 years ago to monitor and prevent heat illness in training camps of the U.S. Army and Marine Corps (Yaglou and Minard 1957). This index has since been adopted by many governments and workplaces to estimate the heat stress/comfort of workers. It is often used in occupational health and safety guidelines for work in hot environments and for use in sports that are characterized by continuous exertion (e.g., marathons) (Budd 2008). It generally incorporates measurements of air temperature, wet-bulb temperature, and black-globe temperature. It has a good correlation with sweat rate, but the estimation gets poorer under low-humidity conditions.

\section{2) $\mathrm{AT}$}

The concept of "apparent temperature" was developed in the 1970s by Steadman (1979a) as an index of "sultriness" and included numerous environmental and physiological variables, such as temperature, clothing cover, physical activity level, solar and terrestrial radiation, internal or core temperature, and other variables (Steadman 1979b, 1984). The index was originally developed for indoor conditions but was modified in the 1980s to include sun and wind to extend it to outdoor 
TABLE 1. Summary of the physiological indices used in the study.

\begin{tabular}{|c|c|c|c|c|}
\hline $\begin{array}{l}\text { Index } \\
\text { name }\end{array}$ & $\begin{array}{c}\text { Index } \\
\text { abbreviation }\end{array}$ & Equation & $\begin{array}{l}\text { Variables } \\
\text { used }\end{array}$ & Source \\
\hline $\begin{array}{l}\text { Wet-bulb globe } \\
\text { temperature }\end{array}$ & WBGT & $\mathrm{WBGT}=0.567 T+0.393 e+3.94$ & $\begin{array}{l}T=\text { dry-bulb temperature }\left({ }^{\circ} \mathrm{C}\right) \\
\text { and } e=\text { water vapor } \\
\text { pressure }(\mathrm{hPa})\end{array}$ & BOM (2010) \\
\hline $\begin{array}{l}\text { Apparent } \\
\text { temperature } \\
\text { excluding } \\
\text { wind }\end{array}$ & $\mathrm{AT}$ & $\mathrm{AT}=-2.653+0.994 T_{a}+0.368(\mathrm{dew})^{2}$ & $\begin{array}{l}T_{a}=\text { air temperature }\left({ }^{\circ} \mathrm{C}\right) \text { and dew }= \\
\text { dewpoint temperature }\left({ }^{\circ} \mathrm{C}\right)\end{array}$ & $\begin{array}{l}\text { Kalkstein and } \\
\text { Valimont (1986) }\end{array}$ \\
\hline $\begin{array}{l}\text { Apparent } \\
\text { temperature } \\
\text { including } \\
\text { wind }\end{array}$ & ATW & $\mathrm{ATW}=T+0.33 e-0.70(\mathrm{ws})-4.00$ & $\begin{array}{l}T=\text { dry-bulb temp }\left({ }^{\circ} \mathrm{C}\right), e=\text { water } \\
\text { vapor pressure }(\mathrm{hPa}), \text { and } \\
\text { ws }=\text { wind speed } \\
\left(\mathrm{m} \mathrm{s}^{-1}\right) \text { at an elev of } 10 \mathrm{~m}\end{array}$ & BOM (2010) \\
\hline $\begin{array}{l}\text { Relative strain } \\
\text { index }\end{array}$ & RSI & $\mathrm{RSI}=\left[10.7+0.74\left(T_{a}-35\right)\right] /\left(44-e_{x}\right)$ & $\begin{array}{l}T_{a}=\text { air temperature }\left({ }^{\circ} \mathrm{C}\right) \\
\text { and } e_{x}=\text { partial water pressure } \\
\text { of the atmosphere } \\
\text { (mm of mercury) }\end{array}$ & $\begin{array}{l}\text { de Garín and } \\
\text { Bejarán (2003) }\end{array}$ \\
\hline $\begin{array}{l}\text { Thom discomfort } \\
\text { index }\end{array}$ & DI & $\mathrm{DI}=T_{a}-0.55[1-0.01(\mathrm{RH})]\left(T_{a}-14.5\right)$ & $\begin{array}{l}T_{a}=\text { air temperature }\left({ }^{\circ} \mathrm{C}\right) \text { and } \mathrm{RH}= \\
\quad \text { relative humidity }(\%)\end{array}$ & Thom (1959) \\
\hline Humidex & & Humidex $=T_{a}+0.5555(e-10)$ & $\begin{array}{l}T_{a}=\text { air temperature }\left({ }^{\circ} \mathrm{C}\right) \text { and } e= \\
\text { water vapor pressure }(\mathrm{hPa})\end{array}$ & $\begin{array}{l}\text { Environment } \\
\text { Canada (2010) }\end{array}$ \\
\hline
\end{tabular}

conditions. The definition of the outdoor AT is based on a mathematical model of an adult walking outdoors in the shade and includes parameterizations for factors such as heat generation and loss, fabric resistance, vapor pressure, wind speed, solar radiation, terrestrial radiation, proportion of body clothed, and other factors (Steadman 1984; Davis et al. 2006). In this study, we used two versions of the AT equation: one including and one excluding the wind speed component (ATW and AT, respectively) (Kalkstein and Valimont 1986; BOM 2010).

\section{3) DI}

The Thom discomfort index (Thom 1959) was developed at the U.S. Weather Bureau (currently the National Weather Service) and has been widely used during the past 40 years to assess heat discomfort (Epstein and Moran 2006).

\section{4) HuMideX}

Humidex (Environment Canada 2010) is a Canadian index that also aims at estimating the perceived temperature based on temperature and humidity. It is equivalent to the heat index that is commonly employed in the United States but uses dewpoint temperature rather than relative humidity. Because the heat index is limited to a predefined range of values of humidity and temperature (i.e., $26.7^{\circ} \mathrm{C}$ and $40 \%$ relative humidity), we decided to use humidex. The Canadian Centre for Occupational Health and Safety provides daily values of humidex intended for the general public. Under certain workplace conditions, humidex can be used to assess thermal comfort of occupational workers, and two sets of index threshold values can be differentiated by the level of acclimatization of workers (i.e., higher threshold values for heat-acclimatized workers) (CCOHS 2010).

\section{5) RSI}

RSI calculates the ratio of sweat evaporation needed for comfort to the amount of evaporation possible given ambient atmospheric conditions. At low temperatures the humidity is relatively independent of the temperature, whereas at high strain levels both temperature and humidity are significantly correlated (Driscoll 1985). Using a set of predefined parameters such as a person dressed in a light business suit walking at a speed of $1 \mathrm{~m} \mathrm{~s}^{-1}$ with wind speed of $0.5 \mathrm{~m} \mathrm{~s}^{-1}$, the equation of the RSI requires only air temperature and partial water vapor pressure as inputs (de Garín and Bejarán 2003). The RSI threshold for thermal strain may be set so that the RSI values can be calculated for any combination of air temperature, humidity, air movement, activity, radiation load, clothing insulation, and age (Lee 1980). For example, the thresholds are 0.50 and 0.30 for young and elderly people, respectively. We computed RSI with the method of de Garín and Bejarán (2003).

\section{c. Statistical analysis}

We calculated daily values and obtained the probability distribution of each index and temperature indicator. We identified hot days as those that fell into the highest $5 \%, 4 \%, 3 \%, 2 \%, 1 \%$, and $0.5 \%$ of each 


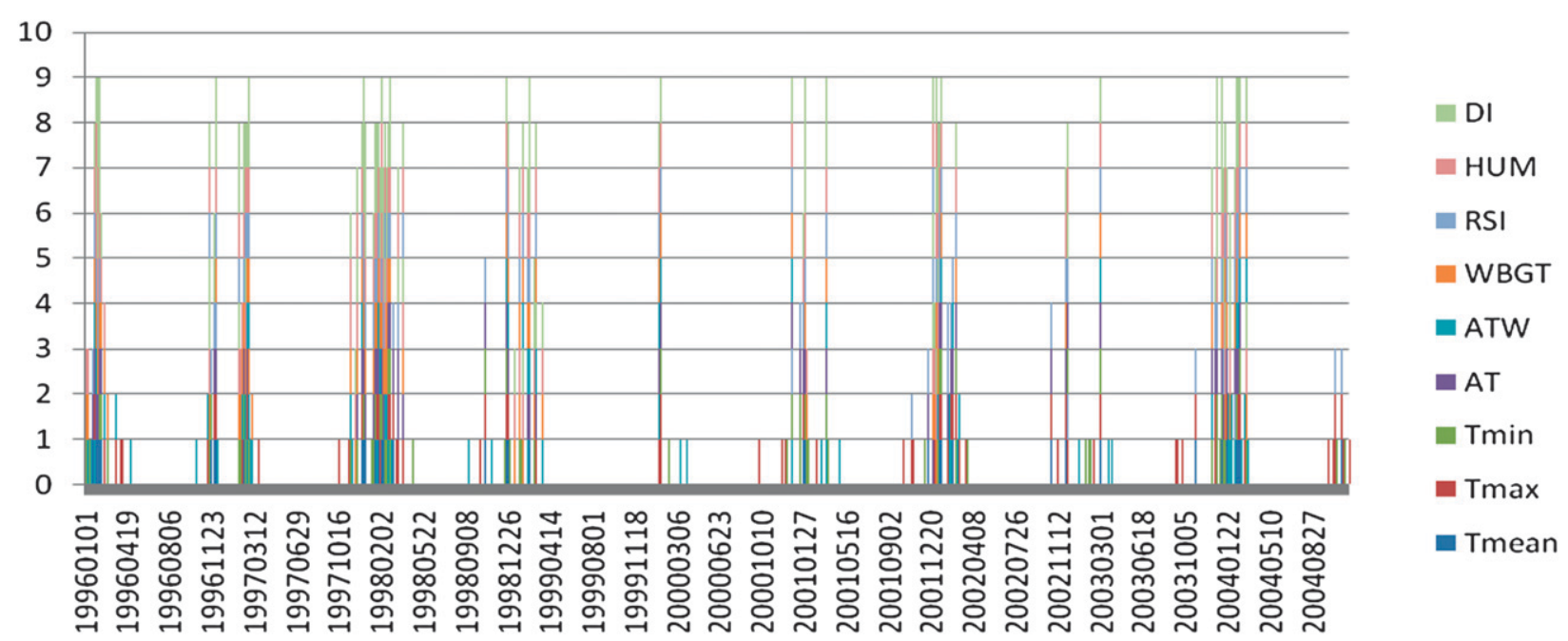

FIG. 1. Time series of the number of indices that selected each day as hot (above the 95th percentile threshold).

index or indicator. We then applied the time-stratified case-crossover method (e.g., Bell et al. 2008). A casecrossover study design compares "case" days with nearby "control" days to identify the difference in exposure (here the difference in the level of temperature), which may explain the differences in the number of cases (i.e., here a number of daily deaths). By matching a case day with nearby control days, we are comparing only recent changes in the exposure; therefore, long-term and seasonal trends can be eliminated. The time-stratified method divides the whole study period into equally sized nonoverlapping sections (i.e., strata); each case day within a stratum is compared only with the control days within that same stratum. The length of the strata is chosen so that it is short enough to remove the seasonal trend but not too short that the case and control days become correlated.

In our study we used a stratum length of 28 days. Within each stratum we only considered the control days that matched a case day by day of week (e.g., if a case day fell on a Monday, it was matched with the 2-3 Monday control days within the 28-day stratum). We then used the conditional logistic regression to calculate the odds ratio (OR) for cases in comparison with controls. The dependent variable was the daily count of mortality; the independent variables included the indices and temperature measures (each fitted separately) and two air pollutants $\left(\mathrm{O}_{3}\right.$ and $\left.\mathrm{PM}_{10}\right)$. Daily measurements of both air pollutants were added as linear independent variables, first separately and then jointly, in the model. Mortality 1 and 2 days after the exposure (lag 1 and lag 2) and mortality on two consecutive hot days were also analyzed.

To compare the ability of all indices to detect excessmortality days, we used a common data-resampling method, the jackknife procedure (Quenouille 1949). The jackknife method attains statistical parameters such as the estimate and its standard error by resampling the existing dataset repeatedly, excluding a single data value during each iteration. It calculates the effect of each data value on the estimate. The advantage of using this technique is that, even if the original estimate of variance is slightly biased, the jackknife method will often eliminate the bias and produce consistent estimates of standard errors (Wonnacott and Wonnacott 1984). In our study, each stratum (28 days) was repeatedly removed from the case-crossover analysis and new estimates were recalculated. The objective of using this method was to determine the reliability of the ORs and the confidence intervals, and to decrease the potential biases. The newly recalculated estimates were then compared. If the range of the estimates for a predictor did not overlap with others, this predictor was assumed to be significantly different.

\section{Results}

There were 3258 days in the study period. Ten percent of those days $(n=331)$ were selected as hot days by at least one discomfort measure (Fig. 1). Almost all of the selected hot days $(n=320)$ occurred within the six warmer months in the Southern Hemisphere (i.e., October-March). Only maximum and minimum temperatures (Tmax and Tmin, respectively) selected the remaining 11 days in the generally cooler months of September and April.

We observed some differences in the way the various indices selected a hot day, suggesting that each index modeled slightly dissimilar comfort criteria (Fig. 1). All 
TABLE 2. Average of temperature, humidity, and air pollutants on days that were above the 95th percentile for each indicator.

\begin{tabular}{|c|c|c|c|c|c|c|c|c|}
\hline & \multicolumn{2}{|c|}{ Avg temperature $\left({ }^{\circ} \mathrm{C}\right)$} & \multicolumn{2}{|c|}{ RH (\%) } & \multicolumn{2}{|c|}{$\mathrm{O}_{3}(\mathrm{ppb})$} & \multicolumn{2}{|c|}{$\mathrm{PM}_{10}\left(\mu \mathrm{g} \mathrm{m}^{-3}\right)$} \\
\hline & Case & Control & Case & Control & Case & Control & Case & Control \\
\hline Avg temperature & 27.5 & 19.4 & 70.9 & 71.9 & 14.5 & 11.1 & 20.8 & 16.4 \\
\hline Max temperature & 26.8 & 19.5 & 68.3 & 72.0 & 15.8 & 11.1 & 22.7 & 16.3 \\
\hline Min temperature & 26.9 & 19.5 & 74.9 & 71.7 & 11.9 & 11.3 & 17.7 & 16.5 \\
\hline Apparent temperature excluding wind & 27.5 & 19.5 & 71.7 & 71.8 & 14.5 & 11.1 & 20.1 & 16.4 \\
\hline Apparent temperature including wind & 26.5 & 19.6 & 75.6 & 71.7 & 14.0 & 11.2 & 17.2 & 16.6 \\
\hline Wet-bulb globe temperature & 27.3 & 19.5 & 76.1 & 71.6 & 13.1 & 11.2 & 17.7 & 16.5 \\
\hline Humidex & 27.3 & 19.5 & 75.6 & 71.6 & 13.4 & 11.2 & 17.8 & 16.5 \\
\hline Thom discomfort index & 27.4 & 19.5 & 74.4 & 71.7 & 13.8 & 11.2 & 18.6 & 16.5 \\
\hline Relative strain index & 27.6 & 19.5 & 70.6 & 71.9 & 14.5 & 11.1 & 21.5 & 16.3 \\
\hline
\end{tabular}

indices selected case days that had on average a higher daily mean temperature (Tmean) than the control days (Table 2). Tmean, RSI, and AT selected days with the highest average temperatures, whereas Tmax and ATW selected days with the lowest average temperatures. Fewer clear patterns occurred in terms of the humidity levels: some indices selected case days that had higher humidity than the control days (Tmin, ATW, WBGT, DI, and humidex) and some did not (Tmean, Tmax, AT, and RSI). The level of both air pollutants was generally higher on the case days in comparison with the control days (Table 2).

Several indices and temperature measures were highly correlated (Table 3). The highest correlation was between Tmean, AT, and DI and also between WBGT and humidex. Least correlated were all indices/temperatures and relative humidity.

The ORs associated with different indices (Table 4) reveal that people were significantly more likely to die on hot (case) days than on neighboring (control) days, with mortality ORs ranging from 1.08 to 1.48 [with associated $95 \%$ confidence intervals (CIs) from 1.02 to 1.14 and from 1.30 to 1.68 , respectively]. In general, we found that the higher the discomfort level on the case days (95th-99.5th percentiles) was, the higher was the probability of death. Adjusting for air pollutants lowered the ORs slightly for all indices, with the lowest ORs when both $\mathrm{O}_{3}$ and $\mathrm{PM}_{10}$ were included in the model (Table 4). These ORs still remained significant for most of the indices/temperature indicators across the 95th99.5th-percentile range, however. Only ORs for ATW at the 99th and 99.5th percentiles and for Tmin at the 99.5th percentile were not significant when both air pollutants were included in the model.

The OR estimates and the 95th-percentile CIs, acquired from the case-crossover analysis for case days that fall into the highest $5 \%, 4 \%, 3 \%, 2 \%, 1 \%$, and $0.5 \%$ of each index, did not reveal any significant differences among most of the indices (Table 4). After recalculating the OR estimates using the jacknife resampling, the case days that fall into the highest $5 \%$ of each index revealed some significant differences between indices and temperature measures (Fig. 2). The estimates of Tmax and Tmin were significantly lower than those of AT and some other indices (ATW, DI, humidex, and WBGT), with the difference ranging between 0.040 and 0.065 of an OR.

Additional analyses were performed to test whether the mortality on lag-1 or lag-2 days significantly increased. The ORs on a lag-1 day were still statistically significant but were lower than the ORs on the same day (results not shown) for all temperatures/indices except for Tmin, which showed a slight increase of OR (i.e., $0.01)$. ORs on lag-2 days were not statistically significant for all measures. When two consecutive days of each indicator were tested, the ORs were lower than when individual days (consisting of individually occurring hot days and consecutive days considered individually) were used; when higher percentiles of two consecutive days

TABLE 3. Pearson correlation coefficients of daily measurements of all indices, temperatures, and RH in Brisbane between 1 January 1996 and 30 November 2004.

\begin{tabular}{lcccccccrrr}
\hline \hline & Tmean & Tmax & Tmin & RH & AT & ATW & WBGT & Humidex & RSI & DI \\
\hline Tmean & 1.00 & 0.90 & 0.92 & 0.07 & 1.00 & 0.74 & 0.97 & 0.98 & 0.95 & 1.00 \\
Tmax & - & 1.00 & 0.70 & -0.09 & 0.89 & 0.73 & 0.83 & 0.84 & 0.88 & 0.88 \\
Tmin & - & - & 1.00 & 0.24 & 0.93 & 0.65 & 0.94 & 0.94 & 0.87 & 0.93 \\
RH & - & - & - & 1.00 & 0.09 & 0.35 & 0.29 & 0.27 & 0.03 & 0.14 \\
AT & - & - & - & - & 1.00 & 0.75 & 0.98 & 0.98 & 0.95 & 1.00 \\
\hline
\end{tabular}


were considered, the ORs became frequently insignificant (results not shown).

\section{Discussion}

Our assessment of various composite indices and temperature measures in the subtropical city of Brisbane showed that all indices and temperature measures can predict heat-related deaths to some extent. We found some differences in performance among these measures. As an indicator of heat stress, average temperature performed similarly to the more complex indices and could be used interchangeably with them. The performance of maximum and minimum temperatures was poorer than the performance of some indices.

Simple temperature measures have been previously used and advocated as a sufficient measure of heat stress (e.g., Curriero et al. 2002; Nicholls et al. 2008; Vaneckova et al. 2008). Nicholls et al. (2008) investigated the performance of several temperature measures to model heat stress between 1979 and 2001 in Melbourne, Australia. They found thresholds of average and minimum temperatures above which mortality increased, and they advocated the use of a simple temperature measure as being sufficient for setting up a warning system. Our study showed that the use of average temperature was comparable in its performance to more complex biometeorological indices, thus supporting their hypothesis.

Maximum temperature has been used as a variable that models heat-related mortality well (Fouillet et al. 2006; Conti et al. 2007). In our study, maximum and minimum temperatures produced poorer results than did average temperature. This could be due to a sudden change in maximum temperature within a 24 -h period, when the temperature peaks during the day but is followed by a sudden drop due to changes in meteorological conditions. As a result, the population is not exposed to high temperatures for periods of time long enough to cause discomfort. Minimum temperature has been documented to be high during heat-wave periods (Semenza et al. 1996; Le Tertre et al. 2006) but has been rarely modeled as a variable alone; it is usually combined with other variables (e.g., Rey et al. 2007; Nicholls et al. 2008). When modeling the days that fell into the 99th percentile in our study, both average and minimum temperatures were comparable to the performance of the composite indices. Given that this occurred only at the 99th percentile, we argue that average temperature is a more stable indicator of heat stress on the Brisbane population than is minimum temperature. Combinations of both minimum and maximum temperatures are more likely to be used in heat-related research, to capture the effect of warm nights that impede the body's recovery after a hot day. Average temperature may be a better indicator because it is more likely to represent the temperature level across the whole $24 \mathrm{~h}$.

The role of humidity on thermal comfort is complex. It is intuitive to assume that simple temperature measures without consideration of the level of humidity may not be sufficient in assessing thermal stress. Apparent temperature combines temperature and humidity and is one of the most used thermal indices in biometeorological studies to predict the impact of heat stress on the local population (e.g., Zanobetti and Schwartz 2008; Baccini et al. 2009). On days when high levels of humidity occur, the human thermoregulatory system may be under additional stress because evaporation, the major mechanism of heat loss, is limited (Kerslake 1972). For the purpose of modeling heat stress, humidity is often combined with a temperature measure. Although all composite indices in our study incorporated some measure of humidity, the role of humidity on the mortality during hot days in Brisbane was not clear and did not seem to make a difference in the final results. Although most indices in our study displayed a linear relationship with average temperature, no obvious relationship was found with relative humidity (data not shown). Thus, the value of each index did not clearly increase with increasing levels of humidity. Some indices selected case days that were more humid than the control day, but overall these indices did not perform differently from those that selected case days with lower humidity than the control days. Brisbane is located in a subtropical climate with summer days that are characterized by high levels of humidity. Sea breeze, which increases humidity, is present on most days. Occasionally hot winds blow from the west and northwest inland regions and result in hot and drier conditions; those days are rare, however. The local population may be well adjusted physiologically to the higher levels of humidity, but it may still be affected by relatively higher temperatures.

Populations in warmer climates are assumed to be well adjusted to the local high temperature as a result of their physiological, behavioral, and technological adaptation. Higher prevalence of air conditioners in regions where high daily temperatures are common during most of the year has been put forward as a protective measure (Davis et al. 2003). Warmer climates also typically show relatively small daily temperature variations in comparison with temperate climates, and heat effects tend to be smaller than those in the temperate locations (Anderson and Bell 2009). Our results and other recent findings have shown, however, that even in warmer climates the population demonstrates an elevated risk of mortality during unusually hot days and that a relative 
TABLE 4. Odds ratios of daily deaths during hot days in Brisbane, 1996-2004. Here $N$ is number of days.

\begin{tabular}{|c|c|c|c|c|c|c|c|c|c|c|}
\hline & \multirow[b]{2}{*}{$N$} & \multicolumn{3}{|c|}{ Nonadjusted } & \multicolumn{3}{|c|}{ Adjusted for $\mathrm{O}_{3}$} & \multicolumn{3}{|c|}{ Adjusted for $\mathrm{O}_{3}$ and $\mathrm{PM}_{10}$} \\
\hline & & OR & $95 \% \mathrm{CI}$ & & OR & $95 \% \mathrm{CI}$ & & OR & $95 \% \mathrm{CI}$ & \\
\hline \multicolumn{11}{|c|}{ Avg temperature (by percentiles) } \\
\hline 95 th & 164 & 1.14 & $1.09,1.20$ & $<0.0001$ & 1.15 & $1.10,1.22$ & $<0.0001$ & 1.12 & $1.06,1.18$ & $<0.0001$ \\
\hline 96th & 130 & 1.13 & $1.07,1.19$ & $<0.0001$ & 1.14 & $1.08,1.21$ & $<0.0001$ & 1.10 & $1.03,1.17$ & $<0.0001$ \\
\hline 97 th & 97 & 1.20 & $1.12,1.27$ & $<0.0001$ & 1.20 & $1.13,1.28$ & $<0.0001$ & 1.16 & $1.08,1.24$ & $<0.0001$ \\
\hline 98th & 64 & 1.23 & $1.14,1.32$ & $<0.0001$ & 1.22 & $1.13,1.31$ & $<0.0001$ & 1.17 & $1.08,1.27$ & $<0.0001$ \\
\hline 99th & 34 & 1.30 & $1.19,1.43$ & $<0.0001$ & 1.29 & $1.18,1.42$ & $<0.0001$ & 1.28 & $1.15,1.42$ & $<0.0001$ \\
\hline 99.5 th & 16 & 1.47 & $1.29,1.67$ & $<0.0001$ & 1.46 & $1.28,1.66$ & $<0.0001$ & 1.40 & $1.21,1.62$ & $<0.0001$ \\
\hline \multicolumn{11}{|c|}{ Max temperature (by percentiles) } \\
\hline 95 th & 164 & 1.10 & $1.05,1.16$ & $<0.0001$ & 1.11 & $1.06,1.17$ & $<0.0001$ & 1.09 & $1.04,1.15$ & 0.0009 \\
\hline 96th & 132 & 1.13 & $1.07,1.19$ & $<0.0001$ & 1.14 & $1.08,1.20$ & $<0.0001$ & 1.11 & $1.05,1.17$ & 0.0004 \\
\hline 97th & 100 & 1.15 & $1.08,1.22$ & $<0.0001$ & 1.15 & $1.08,1.22$ & $<0.0001$ & 1.13 & $1.06,1.20$ & 0.0003 \\
\hline 98th & 67 & 1.18 & $1.10,1.27$ & $<0.0001$ & 1.18 & $1.10,1.27$ & $<0.0001$ & 1.15 & $1.06,1.24$ & 0.0007 \\
\hline 99th & 33 & 1.18 & $1.07,1.30$ & 0.0002 & 1.17 & $1.06,1.29$ & 0.0020 & 1.12 & $1.00,1.24$ & 0.0442 \\
\hline 99.5 th & 15 & 1.30 & $1.13,1.50$ & $<0.0001$ & 1.29 & $1.13,1.49$ & 0.0003 & 1.21 & $1.04,1.41$ & 0.0162 \\
\hline \multicolumn{11}{|c|}{ Min temperature (by percentiles) } \\
\hline 95 th & 164 & 1.11 & $1.05,1.16$ & 0.0001 & 1.11 & $1.06,1.17$ & $<0.0001$ & 1.08 & $1.02,1.14$ & 0.0051 \\
\hline 96th & 127 & 1.15 & $1.08,1.21$ & $<0.0001$ & 1.15 & $1.08,1.21$ & $<0.0001$ & 1.11 & $1.05,1.18$ & 0.0006 \\
\hline 97th & 95 & 1.14 & $1.07,1.22$ & $<0.0001$ & 1.15 & $1.08,1.22$ & $<0.0001$ & 1.11 & $1.03,1.19$ & 0.0035 \\
\hline 98th & 69 & 1.20 & $1.12,1.29$ & $<0.0001$ & 1.21 & $1.12,1.30$ & $<0.0001$ & 1.18 & $1.09,1.28$ & $<0.0001$ \\
\hline 99th & 31 & 1.30 & $1.18,1.43$ & $<0.0001$ & 1.29 & $1.17,1.42$ & $<0.0001$ & 1.27 & $1.13,1.42$ & $<0.0001$ \\
\hline 99.5th & 18 & 1.23 & $1.08,1.40$ & 0.0016 & 1.22 & $1.07,1.39$ & 0.0023 & 1.17 & $1.00,1.36$ & 0.0470 \\
\hline \multicolumn{11}{|c|}{ Apparent temperature (excluding wind; by percentiles) } \\
\hline 95 th & 162 & 1.15 & $1.10,1.21$ & $<0.0001$ & 1.16 & $1.10,1.23$ & $<0.0001$ & 1.13 & $1.06,1.19$ & $<0.0001$ \\
\hline 96th & 129 & 1.17 & $1.10,1.23$ & $<0.0001$ & 1.18 & $1.11,1.24$ & $<0.0001$ & 1.14 & $1.07,1.21$ & $<0.0001$ \\
\hline 97th & 97 & 1.19 & $1.12,1.26$ & $<0.0001$ & 1.19 & $1.12,1.27$ & $<0.0001$ & 1.15 & $1.08,1.24$ & $<0.0001$ \\
\hline 98th & 64 & 1.25 & $1.17,1.35$ & $<0.0001$ & 1.25 & $1.16,1.34$ & $<0.0001$ & 1.20 & $1.11,1.30$ & $<0.0001$ \\
\hline 99th & 32 & 1.31 & $1.19,1.44$ & $<0.0001$ & 1.30 & $1.18,1.43$ & $<0.0001$ & 1.29 & $1.16,1.44$ & $<0.0001$ \\
\hline 99.5 th & 16 & 1.48 & $1.30,1.68$ & $<0.0001$ & 1.46 & $1.28,1.67$ & $<0.0001$ & 1.41 & $1.22,1.64$ & $<0.0001$ \\
\hline \multicolumn{11}{|c|}{ Apparent temperature (including wind; by percentiles) } \\
\hline 95th & 136 & 1.16 & $1.10,1.22$ & $<0.0001$ & 1.17 & $1.10,1.23$ & $<0.0001$ & 1.14 & $1.08,1.21$ & $<0.0001$ \\
\hline 96th & 107 & 1.18 & $1.11,1.25$ & $<0.0001$ & 1.19 & $1.12,1.26$ & $<0.0001$ & 1.14 & $1.07,1.22$ & $<0.0001$ \\
\hline 97th & 80 & 1.17 & $1.10,1.25$ & $<0.0001$ & 1.18 & $1.10,1.26$ & $<0.0001$ & 1.14 & $1.06,1.22$ & 0.0005 \\
\hline 98th & 59 & 1.18 & $1.10,1.27$ & $<0.0001$ & 1.19 & $1.10,1.28$ & $<0.0001$ & 1.14 & $1.05,1.24$ & 0.0021 \\
\hline 99th & 32 & 1.14 & $1.03,1.26$ & 0.0108 & 1.15 & $1.03,1.27$ & 0.0096 & 1.11 & $0.99,1.23$ & 0.0795 \\
\hline 99.5 th & 19 & 1.23 & $1.08,1.40$ & 0.0016 & 1.22 & $1.07,1.39$ & 0.0026 & 1.16 & $1.00,1.34$ & 0.0521 \\
\hline \multicolumn{11}{|c|}{ Wet-bulb globe temperature (by percentiles) } \\
\hline 95th & 162 & 1.16 & $1.11,1.23$ & $<0.0001$ & 1.17 & $1.11,1.24$ & $<0.0001$ & 1.14 & $1.08,1.21$ & $<0.0001$ \\
\hline 96th & 129 & 1.18 & $1.11,1.25$ & $<0.0001$ & 1.19 & $1.12,1.26$ & $<0.0001$ & 1.15 & $1.08,1.22$ & $<0.0001$ \\
\hline 97 th & 97 & 1.20 & $1.17,1.28$ & $<0.0001$ & 1.21 & $1.13,1.29$ & $<0.0001$ & 1.16 & $1.09,1.25$ & $<0.0001$ \\
\hline 98th & 64 & 1.26 & $1.17,1.35$ & $<0.0001$ & 1.26 & $1.17,1.36$ & $<0.0001$ & 1.22 & $1.13,1.32$ & $<0.0001$ \\
\hline 99th & 32 & 1.28 & $1.16,1.41$ & $<0.0001$ & 1.29 & $1.17,1.43$ & $<0.0001$ & 1.28 & $1.14,1.43$ & $<0.0001$ \\
\hline 99.5 th & 16 & 1.28 & $1.12,1.46$ & 0.0003 & 1.27 & $1.11,1.45$ & 0.0005 & 1.21 & $1.04,1.40$ & 0.0162 \\
\hline \multicolumn{11}{|c|}{ Relative strain index (by percentiles) } \\
\hline 95th & 162 & 1.14 & $1.09,1.20$ & $<0.0001$ & 1.15 & $1.09,1.21$ & $<0.0001$ & 1.11 & $1.05,1.18$ & 0.0001 \\
\hline 96th & 129 & 1.14 & $1.08,1.20$ & $<0.0001$ & 1.14 & $1.08,1.21$ & $<0.0001$ & 1.10 & $1.03,1.17$ & 0.0024 \\
\hline 97th & 97 & 1.20 & $1.12,1.27$ & $<0.0001$ & 1.20 & $1.13,1.28$ & $<0.0001$ & 1.17 & $1.09,1.25$ & $<0.0001$ \\
\hline 98th & 64 & 1.23 & $1.14,1.32$ & $<0.0001$ & 1.22 & $1.14,1.32$ & $<0.0001$ & 1.17 & $1.08,1.26$ & 0.0001 \\
\hline 99th & 32 & 1.30 & $1.19,1.43$ & $<0.0001$ & 1.29 & $1.18,1.42$ & $<0.0001$ & 1.28 & $1.15,1.42$ & $<0.0001$ \\
\hline 99.5th & 16 & 1.48 & $1.30,1.68$ & $<0.0001$ & 1.46 & $1.28,1.67$ & $<0.0001$ & 1.41 & $1.22,1.64$ & $<0.0001$ \\
\hline \multicolumn{11}{|c|}{ Humidex (by percentiles) } \\
\hline 95th & 162 & 1.16 & $1.10,1.22$ & $<0.0001$ & 1.17 & $1.11,1.24$ & $<0.0001$ & 1.14 & $1.08,1.21$ & $<0.0001$ \\
\hline 96th & 129 & 1.18 & $1.11,1.25$ & $<0.0001$ & 1.19 & $1.12,1.26$ & $<0.0001$ & 1.15 & $1.08,1.22$ & $<0.0001$ \\
\hline 97th & 97 & 1.20 & $1.13,1.28$ & $<0.0001$ & 1.21 & $1.13,1.29$ & $<0.0001$ & 1.17 & $1.09,1.25$ & $<0.0001$ \\
\hline 98th & 64 & 1.24 & $1.15,1.33$ & $<0.0001$ & 1.25 & $1.16,1.35$ & $<0.0001$ & 1.21 & $1.12,1.31$ & $<0.0001$ \\
\hline 99th & 32 & 1.28 & $1.16,1.41$ & $<0.0001$ & 1.29 & $1.17,1.43$ & $<0.0001$ & 1.28 & $1.14,1.43$ & $<0.0001$ \\
\hline 99.5 th & 16 & 1.34 & $1.19,1.54$ & $<0.0001$ & 1.34 & $1.18,1.53$ & $<0.0001$ & 1.30 & $1.12,1.50$ & 0.0006 \\
\hline
\end{tabular}


TABLE 4. (Continued)

\begin{tabular}{|c|c|c|c|c|c|c|c|c|c|c|}
\hline & \multirow[b]{2}{*}{$N$} & \multicolumn{3}{|c|}{ Nonadjusted } & \multicolumn{3}{|c|}{ Adjusted for $\mathrm{O}_{3}$} & \multicolumn{3}{|c|}{ Adjusted for $\mathrm{O}_{3}$ and $\mathrm{PM}_{10}$} \\
\hline & & OR & $95 \% \mathrm{CI}$ & & OR & $95 \%$ CI & & OR & $95 \% \mathrm{CI}$ & \\
\hline \multicolumn{11}{|c|}{ Thom discomfort index (by percentiles) } \\
\hline 95 th & 162 & 1.16 & $1.10,1.22$ & $<0.0001$ & 1.15 & $1.10,1.21$ & $<0.0001$ & 1.14 & $1.08,1.21$ & $<0.0001$ \\
\hline 96th & 130 & 1.18 & $1.12,1.25$ & $<0.0001$ & 1.20 & $1.13,1.27$ & $<0.0001$ & 1.16 & $1.09,1.23$ & $<0.0001$ \\
\hline 97th & 97 & 1.19 & $1.11,1.26$ & $<0.0001$ & 1.19 & $1.12,1.27$ & $<0.0001$ & 1.15 & $1.07,1.23$ & $<0.0001$ \\
\hline 98th & 65 & 1.27 & $1.18,1.36$ & $<0.0001$ & 1.28 & $1.19,1.38$ & $<0.0001$ & 1.23 & $1.14,1.34$ & $<0.0001$ \\
\hline 99 th & 32 & 1.33 & $1.21,1.46$ & $<0.0001$ & 1.32 & $1.20,1.46$ & $<0.0001$ & 1.31 & $1.17,1.46$ & $<0.0001$ \\
\hline 99.5th & 16 & 1.37 & $1.21,1.56$ & $<0.0001$ & 1.36 & $1.19,1.55$ & $<0.0001$ & 1.32 & $1.14,1.53$ & 0.0003 \\
\hline
\end{tabular}

measure seems to be a better predictor of the heatrelated vulnerability than an absolute measure (Gouveia et al. 2003; Anderson and Bell 2009; Chau et al. 2009; Tong et al. 2010; Yu et al. 2010).

Even though several measures of thermal stress were used in previous studies (Basu et al. 2008; Zanobetti and Schwartz 2008; Papanastasiou et al. 2010), a systematic assessment of the performances of these indices at a single location has rarely been conducted. Davis et al. (2006) compared the performances of various biometeorological indices and the spatial synoptic classification index, an airmass-based categorical classification of meteorological conditions. They found a very small difference in performance among the indices. A more recent study of several U.S. cities also found that various indices and temperature measures have similar ability to predict the weather-mortality relationship (Barnett et al. 2010). Our findings support these results.

In our study, all indices selected days on which mortality was significantly higher; the values of the indices on these high-mortality days suggested conditions that should have only resulted in moderate discomfort in the population of Brisbane, however. Even during the 2004 heat wave that resulted in 75 excess deaths (Tong et al. 2010), the ranges of all indices in our study indicated that people experienced only slight discomfort during those days. For example, the RSI thresholds for risk category for young and older population groups are 0.5 and 0.3 , respectively. In Brisbane, the hot days that fell into the highest 5 percentile had an RSI value of 0.24 , and yet the population had $14 \%$ higher probability of dying on these days. In the case of DI, the highest 5 percentile of the index selected days with a value of 25.6, which increased to 27.3 at the 99 th percentile but never reached the critical value of 28 associated with the onset of physical and cognitive deterioration. Values of humidex between the 95th and 99.5th percentiles also fell within the "moderate discomfort" category, and the values of apparent temperature (without wind) did not even reach the light discomfort level. The general thresholds marking the onset of discomfort for a specific index may need to be adjusted according to the vulnerability of the local population.

Previous studies have considered the impact of lags and several consecutive days of extreme temperatures on health (e.g., Anderson and Bell 2009). In our study, ORs for lag 1, lag 2, and two consecutive hot days were lower than those on the individual days of exposure. The effect of extreme hot weather on the population of Brisbane was rather immediate, with the largest number of excess deaths on the same day of exposure to hot weather (i.e., lag 0). Mortality displacement could be a possible explanation for acute increases in the number of deaths; those who are in fragile condition and would die regardless of weather in a short period of time could make up a larger proportion of the heat-related deaths. Further study considering the years of life lost rather than numbers of deaths during hot days would help to build a better picture of the impacts of hot weather on public health and to assess whether they could be avoided with proper intervention.

Unlike some of the previous studies comparing the performance of several measures of heat stress, our study also incorporated the potential effect of air pollutants

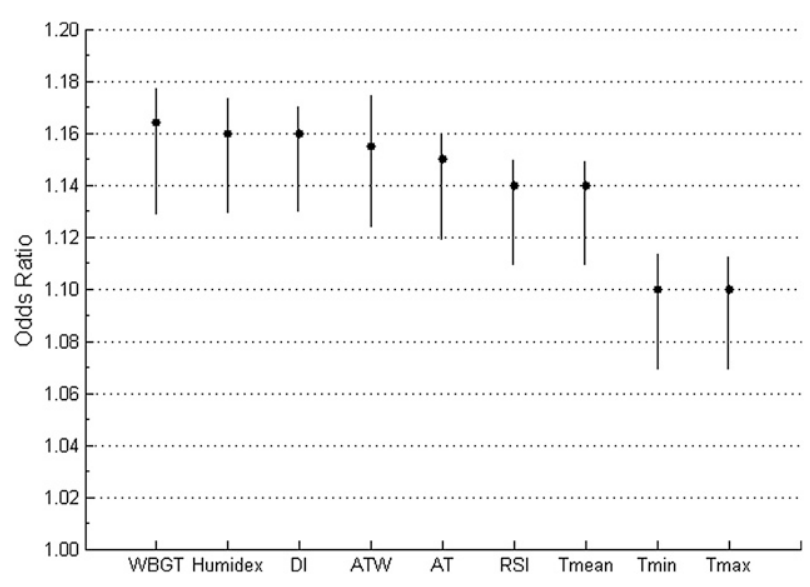

FIG. 2. The range of estimates by the jackknife method of ORs for each index. Vertical bars denote the range values between the 25 th and 75 th percentiles. 
on excess mortality during hot days. Air pollution can account for up to $38 \%$ of deaths on such days (Stedman 2004). Both $\mathrm{O}_{3}$ and $\mathrm{PM}_{10}$ had previously been associated with increased mortality in Brisbane (Morawska et al. 2002; Simpson et al. 2005; Ren et al. 2008). Our study found that both air pollutants contributed to mortality to some degree, confirming results from other studies (e.g., Stedman 2004; Stafoggia et al. 2008). A new type of index could incorporate information about air pollution. This would provide an integrated warning message for the public, avoiding the possibility of contradictory messages arising from the use of two independent indices (i.e., air pollution monitoring and heat-warning index).

In general, the concentrations of air pollutants vary spatially within a city. Previous study in Brisbane found that the $\mathrm{O}_{3}$ measurements did not vary spatially; therefore, any station within the city could be used as representative of the $\mathrm{O}_{3}$ exposure. In the case of $\mathrm{PM}_{10}$, the concentrations were heterogeneously distributed: more localized and usually higher in close proximity to its sources (Morawska et al. 2002). The main source of $\mathrm{PM}_{10}$ in Brisbane is car traffic, with some minor contributions from local industry and occasionally high levels that are due to controlled or wild bushfires (DERM 2010). It can be argued that our results could somehow be affected by our choice of $\mathrm{PM}_{10}$ monitoring station. By selecting only one station, the resulting mortality ORs could be biased by the spatially varying levels of $\mathrm{PM}_{10}$. As mentioned before, the station selected is located at an elevated position and therefore is less subject to local fluctuations in levels of $\mathrm{PM}_{10}$. We therefore believe that the inclusion of data from other available stations that are in some cases designed to measure localized levels of $\mathrm{PM}_{10}$ would not improve our results. Temperature is also presumed to vary spatially within the LGA boundaries, but we could not account for this in our study because of the limited spatial data on both exposure and outcomes.

We have identified some limitations in our study. First, it was conducted at one location only, which limits the generalization of the results. A subsequent study is under way to compare various indices at climatically different locations. Second, we did not explore the effect of heat on the elderly and by specific cause of mortality. The elderly are considered to be the most vulnerable age group. Most daily deaths normally fall into the older portion of the population, however, and therefore our results are probably correlated with those expected for the elderly group. Cardiovascular and respiratory diseases have been commonly found to be a major cause of death during hot days (e.g., Rey et al. 2007). Mortality from a wide variety of other causes also increases during hot days (e.g., Kalkstein and Davis 1989; Conti et al.
2007). In this study we considered total organic cause of death to include all causes of death that were potentially heat related. A next step will consist of studying different age groups and various specific causes of death. It also would be beneficial to investigate the performance of the indices using nonfatal outcomes. Under extremely hot environmental temperatures, increases in nonfatal health impacts are to be expected. This should be analyzed to verify whether the small differences we observed in the indices and the average temperature hold for nonfatal outcomes as well and to decide whether this framework could be utilized for the development of early-warning systems to particularly vulnerable groups.

\section{Conclusions}

There was no significant difference in the performance of composite indices and the simple average temperature on the extremely hot days in Brisbane during 1996-2004. Over the years more emphasis has been put on the academic accuracy of indices at the expense of their practicality (Epstein and Moran 2006). A warning system based on a simple temperature measure has been previously established (e.g., Pascal et al. 2006), and those based on more complex methods have not been proven to be superior (Hajat et al. 2010). If a simple measure like average temperature performs well at some location, this would be important for emergency planners, because it offers a measure without extra complexities and associated error risks. For the nonscientific population it offers an easy-to-understand risk measure to approximate heat stress, and it would therefore help with the development of public-health intervention strategies. More research is warranted to confirm if average temperature could be the basis of an inexpensive weather-health warning system across different places.

Acknowledgments. We acknowledge the statistical help of Adrian Barnett. We also thank the Office of Economic and Statistical Research of the Queensland Treasury for providing the mortality data for this study. Last, we thank the three anonymous reviewers, whose input improved the analysis and the clarity of the manuscript.

\section{REFERENCES}

Anderson, B. G., and M. L. Bell, 2009: Weather-related mortality: How heat, cold, and heat waves affect mortality in the United States. Epidemiology, 20, 205-213.

ASHRAE, 2004: ASHRAE Standard. Thermal Environmental Conditions for Human Occupancy. American Society of Heating, Refrigerating and Air-Conditioning Engineers Standard 55-2004, $28 \mathrm{pp}$.

Baccini, M., and Coauthors, 2009: Impact of heat on mortality in 15 European cities: Attributable deaths under different weather scenarios. J. Epidemiol. Community Health, 65, 64-70. 
Barnett, A. G., S. Tong, and A. C. A. Clements, 2010: What measure of temperature is the best predictor of mortality? Environ. Res., 110, 604-611.

Basu, R., W.-Y. Feng, and B. D. Ostro, 2008: Characterizing temperature and mortality in nine California counties. Epidemiology, 19, 138-145.

Bell, M. L., M. S. O’Neill, N. Ranjit, V. H. Borja-Aburto, L. A. Cifuentes, and N. C. Gouveia, 2008: Vulnerability to heat-related mortality in Latin America: A case-crossover study in São Paulo, Brazil, Santiago, Chile and Mexico City, Mexico. Int. J. Epidemiol., 37, 796-804.

BOM, cited 2010: Thermal comfort observations. Bureau of Meteorology. [Available online at http://www.bom.gov.au/info/ thermal_stress/.]

Budd, G. M., 2008: Wet-bulb globe temperature (WBGT)—Its history and its limitations. J. Sci. Med. Sport, 11, 20-32.

CCOHS, cited 2010: Humidex rating and work. Canadian Centre for Occupational Health and Safety. [Available online at http:// www.ccohs.ca/oshanswers/phys_agents/humidex.html.]

Chau, P. H., K. C. Chan, and J. Woo, 2009: Hot weather warning might help to reduce elderly mortality in Hong Kong. Int. J. Biometeor., 53, 461-468.

Conti, S., M. Masocco, P. Meli, G. Minelli, E. Palummeri, R. Solimini, V. Toccaceli, and M. Vichi, 2007: General and specific mortality among the elderly during the 2003 heat wave in Genoa (Italy). Environ. Res., 103, 267-274.

Curriero, F. C., K. S. Heiner, J. M. Samet, S. L. Zeger, L. Strug, and J. A. Patz, 2002: Temperature and mortality in 11 cities of the eastern United States. Amer. J. Epidemiol., 155, 80-87.

Davis, R. E., P. C. Knappenberger, P. J. Michaels, and W. M. Novicoff, 2003: Changing heat-related mortality in the United States. Environ. Health Perspect., 111, 1712-1718.

—, D. Knight, D. Hondula, and P. C. Knappenberger, 2006: A comparison of biometeorological comfort indices and human mortality during heat waves in the United States. Preprints, 17th Conf. on Biometeorology and Aerobiology, San Diego, CA, Amer. Meteor. Soc., 2.4. [Available online at http://ams. confex.com/ams/pdfpapers/110867.pdf.]

de Garín, A., and R. Bejarán, 2003: Mortality rate and relative strain index in Buenos Aires city. Int. J. Biometeor., 48, 31-36.

DERM, cited 2010: Environmental management: South-east Queensland monitoring stations. Queensland Department of Environment and Resources Management. [Available online at http://www.derm.qld.gov.au/environmental_management/ air/air_quality_monitoring/air_monitoring_network/southeast_ queensland_region.html.]

Driscoll, D. M., 1985: Human health. Handbook of Applied Meteorology, D. D. Houghton, Ed., John Wiley and Sons, 778-814.

Environment Canada, cited 2010: What is the "humidex"? [Available online at http://www.weatheroffice.gc.ca/mainmenu/faq_e. html\#weather4b.]

Epstein, Y., and D. S. Moran, 2006: Thermal comfort and the heat stress indices. Ind. Health, 44, 388-398.

Fouillet, A., and Coauthors, 2006: Excess mortality related to the August 2003 heat wave in France. Int. Arch. Occup. Environ. Health, 80, 16-24.

Gouveia, N., S. Hajat, and B. Armstrong, 2003: Socioeconomic differentials in the temperature-mortality relationship in São Paulo, Brazil. Int. J. Epidemiol., 32, 390-397.

Hajat, S., and Coauthors, 2010: Heat-health warning systems: A comparison of the predictive capacity of different approaches to identifying dangerously hot days. Amer. J. Public Health, 100, $1137-1144$.
Hart, M., R. de Dear, and R. Hyde, 2006: A synoptic climatology of tropospheric ozone episodes in Sydney, Australia. Int. J. Climatol., 26, 1635-1649.

Höppe, P., 1999: The physiological equivalent temperature-A universal index for the biometeorological assessment of the thermal environment. Int. J. Biometeor., 43, 71-75.

Kalkstein, L. S., and K. M. Valimont, 1986: An evaluation of summer discomfort in the United States using a relative climatological index. Bull. Amer. Meteor. Soc., 67, 842-848.

- and R. E. Davis, 1989: Weather and human mortality: An evaluation of demographic and interregional responses in the United States. Ann. Assoc. Amer. Geogr., 79, 44-64.

— , P. F. Jamason, J. S. Greene, J. Libby, and L. Robinson, 1996: The Philadelphia hot weather-health watch warning system: Development and application, summer 1995. Bull. Amer. Meteor. Soc., 77, 1519-1528.

Kerslake, D. McK., 1972: The Stress of Hot Environments. Cambridge University Press, 316 pp.

Lee, D. H., 1980: Seventy-five years of searching for a heat index. Environ. Res., 22, 331-356.

Le Tertre, A., and Coauthors, 2006: Impact of the 2003 heat wave on all-cause mortality in 9 French cities. Epidemiology, 17, 75-79.

Metzger, K. B., K. Ito, and T. D. Matte, 2010: Summer heat and mortality in New York: How hot is too hot? Environ. Health Perspect., 118, 80-91.

Morawska, L., D. Vishvakarman, K. Mengersen, and S. Thomas, 2002: Spatial variation of airborne pollutant concentrations in Brisbane, Australia, and its potential impact on population exposure assessment. Atmos. Environ., 36, 3545-3555.

Nicholls, N., C. Skinner, M. Loughnan, and N. Tapper, 2008: A simple heat alert system for Melbourne, Australia. Int. J. Biometeor., 52, 375-384.

O'Neill, M. S., A. Zanobetti, and J. Schwartz, 2003: Modifiers of the temperature and mortality association in seven US cities. Amer. J. Epidemiol., 157, 1074-1082.

Papanastasiou, D. K., D. Melas, T. Bartzanas, and C. Kittas, 2010: Temperature, comfort and pollution levels during heat waves and the role of sea breeze. Int. J. Biometeor., 54, 307-317.

Pascal, M., and Coauthors, 2006: France's heat health watch warning system. Int. J. Biometeor., 50, 144-153.

Quenouille, M. H., 1949: Approximate tests of correlation in time series. J. Roy. Stat. Soc., 11A, 18-84.

Ren, C., G. M. Williams, L. Morawska, K. Mengersen, and S. Tong, 2008: Ozone modifies associations between temperature and cardiovascular mortality: Analysis of the NMMAPS data. Occup. Environ. Med., 65, 255-260.

Rey, G., E. Jougla, A. Fouillet, G. Pavillon, P. Bessemoulin, P. Frayssinet, J. Clavel, and D. Hémon, 2007: The impact of major heat waves on all-cause and cause-specific mortality in France from 1971 to 2003. Int. Arch. Occup. Environ. Health, 80, 615-626.

Roberts, S., 2004: Interactions between particulate air pollution and temperature in air pollution mortality time series studies. Environ. Res., 96, 328-337.

Semenza, J. C., C. H. Rubin, K. H. Falter, J. D. Selanikio, W. D. Flanders, H. L. Howe, and J. L. Wilhelm, 1996: Heat-related deaths during the July 1995 heat wave in Chicago. N. Engl. J. Med., 335, 84-90.

Sheridan, S. C., and L. S. Kalkstein, 2004: Progress in heat watchwarning system technology. Bull. Amer. Meteor. Soc., 85, 19311941.

Simpson, R., G. Williams, A. Petroeschevsky, T. Best, G. Morgan, L. Denison, A. Hinwood, and G. Neville, 2005: The short-term 
effects of air pollution on daily mortality in four Australian cities. Aust. N. Z. J. Public Health, 29, 205-212.

Smargiassi, A., M. S. Goldberg, C. Plante, M. Fournier, Y. Baudouin, and T. Kosatsky, 2009: Variation of daily warm season mortality as a function of micro-urban heat islands. J. Epidemiol. Community Health, 63, 659-664.

Spagnolo, J., and R. de Dear, 2003: A field study of thermal comfort in outdoor and semi-outdoor environments in subtropical Sydney, Australia. Build. Environ., 38, 721-738.

Stafoggia, M., and Coauthors, 2008: Does temperature modify the association between air pollution and mortality? A multicity case-crossover analysis in Italy. Amer. J. Epidemiol., 167, 14761485.

Steadman, R. G., 1979a: The assessment of sultriness. Part I: A temperature-humidity index based on human physiology and clothing science. J. Appl. Meteor., 18, 861-873.

_, 1979b: The assessment of sultriness. Part II: Effects of wind, extra radiation and barometric pressure on apparent temperature. J. Appl. Meteor., 18, 874-885.

_ 1984: A universal scale of apparent temperature. J. Climate Appl. Meteor., 23, 1674-1687.

Stedman, J. R., 2004: The predicted number of air pollution related deaths in the UK during the August 2003 heat wave. Atmos. Environ., 38, 1087-1090.
Thom, E. C., 1959: The discomfort index. Weatherwise, 12, $57-60$.

Tong, S., C. Ren, and N. Becker, 2010: Excess deaths during the 2004 heat wave in Brisbane, Australia. Int. J. Biometeor., 54, 393-400.

Vaneckova, P., P. J. Beggs, R. J. de Dear, and K. W. J. McCracken, 2008: Effect of temperature on mortality during the six warmer months in Sydney, Australia, between 1993 and 2004. Environ. Res., 108, 361-369.

Watts, J. D., and L. S. Kalkstein, 2004: The development of a warmweather relative stress index for environmental applications. J. Appl. Meteor., 43, 503-513.

Wonnacott, T. H., and R. J. Wonnacott, 1984: Introductory Statistics for Business and Economics. 3rd ed. John Wiley and Sons, $746 \mathrm{pp}$.

Yaglou, C. P., and D. Minard, 1957: Control of heat casualties at military training centers. Amer. Med. Assoc. Arch. Ind. Health, 16, 302-316.

Yu, W., P. Vaneckova, K. Mengersen, X. Pan, and S. Tong, 2010: Is the association between temperature and mortality modified by age, gender and socio-economic status? Sci. Total Environ., 408, 3513-3518.

Zanobetti, A., and J. Schwartz, 2008: Temperature and mortality in nine US cities. Epidemiology, 19, 563-570. 